\title{
Correction to: Pyrolysis characteristic study on seat cushion materials of China's high-speed train
}

\author{
Junhai Liang ${ }^{1} \cdot$ Bingsong Wang ${ }^{1} \cdot{\text { Longlong } Z \mathrm{Zh}^{1} \cdot \text { Hongshuang Wang }}^{2} \cdot$ Changhai $\mathrm{Li}^{2} \cdot$ Shouxiang $\mathrm{Lu}^{2}$
}

Published online: 20 August 2020

○) Akadémiai Kiadó, Budapest, Hungary 2020

Correction to: Journal of Thermal Analysis and Calorimetry
https://doi.org/10.1007/s10973-017-6509-8

In the original version of the article, the order of funding program in the acknowledgement section was published incorrectly. The corrected order of funding program in the acknowledgment section should read as below:

\section{Acknowledgements}

The authors would like to acknowledge financial support sponsored by "the National Key Research and Development Program of China (2016YFB1200505)" and "the
National Key Research and Development Program of China (2016YFB1200403)".

Publisher's Note Springer Nature remains neutral with regard to jurisdictional claims in published maps and institutional affiliations.

The original article can be found online at https://doi.org/10.1007/ s10973-017-6509-8.

Shouxiang Lu

sxlu@ustc.edu.cn

1 CRRC Qingdao Sifang CO., LTD, Qingdao 266111, China

2 State Key Laboratory of Fire Science, University of Science and Technology of China, Hefei 230027, China 